\title{
Split feasibility and fixed-point problems for asymptotically quasi-nonexpansive mappings
}

\author{
Jitsupa Deepho and Poom Kumam*
}

\section{"Correspondence:}

poom.kum@kmutt.ac.th

Department of Mathematics,

Faculty of Science, King Mongkut's

University of Technology Thonburi

(KMUTT), 126 Pracha Uthit Rd., Bang

Mod, Thrung Khru, Bangkok 10140,

Thailand

\begin{abstract}
The purpose of this paper is to introduce and analyze a weakly convergent theorem by using the regularized method and the relaxed extragradient method for finding a common element of the solution set $\Gamma$ of the split feasibility problem and $\operatorname{Fix}(T)$ of fixed points of asymptotically quasi-nonexpansive mappings $T$ in the setting of infinite-dimensional Hilbert spaces. Consequently, we prove that the sequence generated by the proposed algorithm converges weakly to an element of Fix $(T) \cap \Gamma$ under mild assumptions.

MSC: $47 \mathrm{H} 09 ; 47 \mathrm{~J} 25 ; 65 \mathrm{~K} 10$

Keywords: split feasibility problems; fixed point problems; relaxed extragradient methods; regularization; asymptotically quasi-nonexpansive mappings; maximal monotone mappings
\end{abstract}

\section{Introduction}

In 1994, Censor and Elfving [1] first introduced the split feasibility problem (SFP) in finitedimensional Hilbert spaces for modeling inverse problems which arise from phase retrievals and in medical image reconstruction [2]. It was found that the SFP can also be used to model intensity-modulated radiation therapy (IMRT) (see [3-6]). Very recently, $\mathrm{Xu}$ [7] considered the SFP in the framework of infinite-dimensional Hilbert spaces. In this setting, the SFP is formulated as the problem of finding a point $x^{*}$ with the property

$$
x^{*} \in C \text { and } A x^{*} \in Q \text {, }
$$

where $C$ and $Q$ are the nonempty closed convex subsets of the infinite-dimensional real Hilbert spaces $H_{1}$ and $H_{2}$, respectively. Let $A \in B\left(H_{1}, H_{2}\right)$, where $B\left(H_{1}, H_{2}\right)$ denotes the family of all bounded linear operators from $H_{1}$ to $H_{2}$.

We use $\Gamma$ to denote the solution set of the SFP, i.e.,

$$
\Gamma=\{x \in C: A x \in Q\} .
$$

Assume that the SFP is consistent (i.e., (1.1) has a solution) so that $\Gamma$ is closed, convex and nonempty. A special case of the SFP is the following convex constrained linear inverse

\section{Springer}

(c) 2013 Deepho and Kumam; licensee Springer. This is an Open Access article distributed under the terms of the Creative Commons Attribution License (http://creativecommons.org/licenses/by/2.0), which permits unrestricted use, distribution, and reproduction in any medium, provided the original work is properly cited. 
problem:

$$
\text { find } x \in C \text { such that } A x=b \text {, }
$$

which has extensively been investigated by using the Landweber iterative method [8]:

let $x_{0}$ be arbitrary for $n=0,1, \ldots$, let

$$
x_{n+1}=x_{n}+\gamma A^{T}\left(b-A x_{n}\right) \text {. }
$$

Comparatively, the SFP has received much less attention so far due to the complexity resulting from the set $Q$. Therefore, whether various versions of the projected Landweber iterative method [8] can be extended to solve the SFP remains an interesting open topic.

The original algorithm given in [1] involves the computation of the inverse $A^{-1}$ (assuming the existence of the inverse of $A$ ):

$$
x_{k+1}=A^{-1} P_{Q}\left(P_{A(C)}\left(A x_{k}\right)\right), \quad k \geq 0,
$$

where $C, Q \subset \mathbb{R}^{n}$ are closed convex sets, $A$ is a full rank $n \times n$ matrix and $A(C)=\{y \in$ $\left.\mathbb{R}^{n} \mid y=A x, x \in C\right\}$, and thus has not become popular.

A more popular algorithm that solves the SFP seems to be the CQ algorithm of Byrne [2, 9] which is found to be a gradient-projection method (GPM) in convex minimization. It is also a special case of the proximal forward-backward splitting method [10]. The CQ algorithm only involves the computations of the projections $P_{C}$ and $P_{Q}$ onto the sets $C$ and $Q$, respectively, and is therefore implementable in the case where $P_{C}$ and $P_{Q}$ have closed-form expressions (for example, $C$ and $Q$ are closed balls or half-spaces). It remains, however, a challenge on the $C Q$ algorithm in the case where the projection $P_{C}$ and/or $P_{Q}$ fail to have closed-form expressions though theoretically we can prove the (weak) convergence of the algorithm.

Recently, Xu [7] gave a continuation of the study on the CQ algorithm and its convergence. He applied Mann's algorithm to the SFP and proposed an averaged CQ algorithm, which was proved to be weakly convergent to a solution of the SFP. He derived a weak convergence result, which shows that for suitable choices of iterative parameters (including the regularization), the sequence of iterative solutions can converge weakly to an exact solution of the SFP. He also established the strong convergence result, which shows that the minimum-norm solution can be obtained. Later, Deepho and Kumam [11] extended the results of $\mathrm{Xu}$ [7] by introducing and studying the modified Halpern iterative scheme for solving the split feasibility problem (SFP) in the setting of infinite-dimensional Hilbert spaces.

Throughout this paper, we always assume that the SFP is consistent, that is, the solution set $\Gamma$ of the SFP is nonempty. Let $f: H_{1} \rightarrow \mathbb{R}$ be a continuous differentiable function. The minimization problem

$$
\min _{x \in C} f(x):=\frac{1}{2}\left\|A x-P_{Q} A x\right\|^{2}
$$


is ill-posed. Therefore (see [7]), consider the following Tikhonov regularized problem:

$$
\min _{x \in C} f_{\alpha}(x):=\frac{1}{2}\left\|A x-P_{Q} A x\right\|^{2}+\frac{1}{2} \alpha\|x\|^{2},
$$

where $\alpha>0$ is the regularization parameter.

We observe that the gradient

$$
\nabla f_{\alpha}(x)=\nabla f(x)+\alpha I=A^{*}\left(I-P_{Q}\right) A+\alpha I
$$

is $\left(\alpha+\|A\|^{2}\right)$-Lipschitz continuous and $\alpha$-strongly monotone.

Define the Picard iterates

$$
x_{n+1}^{\alpha}=P_{C}\left(I-\gamma\left(A^{*}\left(I-P_{Q}\right) A+\alpha I\right)\right) x_{n}^{\alpha} .
$$

$\mathrm{Xu}$ [7] showed that if SFP (1.1) is consistent, then as $n \rightarrow \infty, x_{n}^{\alpha} \rightarrow x_{\alpha}$ and consequently the strong $\lim _{\alpha \rightarrow 0} x_{\alpha}$ exists and is the minimum-norm solution of the SFP. Note that (1.6) is double-step iteration. $\mathrm{Xu}$ [7] further suggested the following single step regularized method:

$$
x_{n+1}=P_{C}\left(I-\gamma \nabla f_{\alpha_{n}}\right) x_{n}=P_{C}\left(\left(1-\alpha_{n} \gamma_{n}\right) x_{n}-\gamma_{n} A^{*}\left(I-P_{Q}\right) A x_{n}\right) .
$$

He proved that the sequence $\left\{x_{n}\right\}$ generated by (1.7) converges in norm to the minimumnorm solution of the SFP provided the parameters $\left\{\alpha_{n}\right\}$ and $\left\{\gamma_{n}\right\}$ satisfy the following conditions:

(i) $\alpha_{n} \rightarrow 0$ and $0<\gamma_{n}<\frac{\alpha_{n}}{\|A\|^{2}+\alpha_{n}}$;

(ii) $\sum_{n} \alpha_{n} \gamma_{n}=\infty$;

(iii) $\frac{\left|\gamma_{n+1}-\gamma_{n}\right|+\gamma_{n}\left|\alpha_{n+1}-\alpha_{n}\right|}{\left(\alpha_{n+1} \gamma_{n+1}\right)^{2}} \rightarrow 0$.

Motivated by the idea of the relaxed extragradient method and Xu's regularization, Ceng, Ansari and Yao [12] presented the following relaxed extragradient method with regularization for finding a common element of the solution set of the split feasibility problem and the set $\operatorname{Fix}(S)$ of fixed points of a nonexpansive mapping $S$ :

$$
\left\{\begin{array}{l}
x_{0}=x \in C \quad \text { chosen arbitrarily, } \\
y_{n}=\left(1-\beta_{n}\right)+\beta_{n} P_{C}\left(x_{n}-\lambda \nabla f_{\alpha_{n}}\left(x_{n}\right)\right), \\
x_{n+1}=\gamma_{n} x_{n}+\left(1-\gamma_{n}\right) S P_{C}\left(y_{n}-\lambda \nabla f_{\alpha_{n}}\left(y_{n}\right)\right), \quad \forall n \geq 0 .
\end{array}\right.
$$

They only obtained the weak convergence of iterative algorithm (1.8).

The purpose of this paper to study and analyze an relaxed extragradient method with regularization for finding a common element of the solution set $\Gamma$ of the SFP and the set solutions of fixed points for asymptotically quasi-nonexpansive mappings and a Lipschitz continuous mapping in a real Hilbert space. We prove that the sequence generated by the proposed method converges weakly to an element $\hat{x}$ in $\operatorname{Fix}(T) \cap \Gamma$.

\section{Preliminaries}

We first recall some definitions, notations, and conclusions which will be needed in proving our main results. Let $H$ be a real Hilbert space with the inner product $\langle\cdot, \cdot\rangle$ and $\|\cdot\|$ 
and let $C$ be a closed and convex subset of $H$. Let $E$ be a Banach space. A mapping $T: E \rightarrow E$ is said to be demi-closed at origin if for any sequences $\left\{x_{n}\right\} \subset E$ with $x_{n} \rightarrow x^{*}$ and $\left\|(I-T) x_{n}\right\| \rightarrow 0, x^{*}=T x^{*}$. A Banach space $E$ is said to have the Opial property if for any sequence $\left\{x_{n}\right\}$ with $x_{n} \rightarrow x^{*}$,

$$
\liminf _{n \rightarrow \infty}\left\|x_{n}-x^{*}\right\|<\liminf _{n \rightarrow \infty}\left\|x_{n}-y\right\|, \quad \forall y \in E \text { with } y \neq x^{*}
$$

Remark 2.1 It is well known that each Hilbert space possesses the Opial property.

Definition 2.2 Let $H$ be a real Hilbert space, let $C$ be a nonempty and closed convex subset. We denote by $\operatorname{Fix}(T)$ the set of fixed points of $T$, that is, $\operatorname{Fix}(T)=\{x \in C: x=T x\}$. Then $T$ is said to be

(i) nonexpansive if $\|T x-T y\| \leq\|x-y\|$ for all $x, y \in C$;

(ii) quasi-nonexpansive if $\|T x-p\| \leq\|x-p\|$ for all $x \in C$ and $p \in F(T)$;

(iii) asymptotically nonexpansive if there exist a sequence $k_{n} \geq 1$ and $\lim _{n \rightarrow \infty} k_{n}=1$ such that

$$
\left\|T^{n} x-T^{n} y\right\| \leq k_{n}\|x-y\|
$$

for all $x, y \in C$ and $n \geq 1$;

(iv) asymptotically quasi-nonexpansive if there exist a sequence $k_{n} \geq 1$ and $\lim _{n \rightarrow \infty} k_{n}=1$ such that

$$
\left\|T^{n} x-p\right\| \leq k_{n}\|x-p\|
$$

for all $x \in C, p \in F(T)$ and $n \geq 1$;

(v) uniformly L-Lipschitzian if there exists a constant $L>0$ such that

$$
\left\|T^{n} x-T^{n} y\right\| \leq L\|x-y\|
$$

for all $x, y \in C$ and $n \geq 1$.

Remark 2.3 By the above definitions, it is clear that:

(i) a nonexpansive mapping is an asymptotically quasi-nonexpansive mapping;

(ii) a quasi-nonexpansive mapping is an asymptotically-quasi nonexpansive mapping;

(iii) an asymptotically nonexpansive mapping is an asymptotically quasi-nonexpansive mapping.

Proposition 2.4 (see [9]) We have the following assertions.

(i) $T$ is nonexpansive if and only if the complement $I-T$ is $\frac{1}{2}$-ism.

(ii) If $T$ is $v$-ism and $\gamma>0$, then $\gamma T$ is $\frac{v}{\gamma}$-ism.

(iii) $T$ is averaged if and only if the complement $I-T$ is $v$-ism for some $v>\frac{1}{2}$.

Indeed, for $\alpha \in(0,1), T$ is $\alpha$-averaged if and only if $I-T$ is $\frac{1}{2 \alpha}$-ism.

Proposition 2.5 (see $[9,13])$ We have the following assertions.

(i) If $T=(1-\alpha) S+\alpha V$ for some $\alpha \in(0,1)$, $S$ is averaged and $V$ is nonexpansive, then $T$ is averaged. 
(ii) $T$ is firmly nonexpansive if and only if the complement $I-T$ is firmly nonexpansive.

(iii) If $T=(1-\alpha) S+\alpha V$ for some $\alpha \in(0,1)$, $S$ is firmly nonexpansive and $V$ is nonexpansive, then $T$ is averaged.

(iv) The composite of finite many averaged mappings is averaged. That is, if each of the mappings $\left\{T_{i}\right\}_{i=1}^{n}$ is averaged, then so is the composite $T_{1} \circ T_{2} \circ \cdots \circ T_{N}$. In particular, if $T_{1}$ is $\alpha_{1}$-averaged and $T_{2}$ is $\alpha_{2}$-averaged, where $\alpha_{1}, \alpha_{2} \in(0,1)$, then the composite $T_{1} \circ T_{2}$ is $\alpha$-averaged, where $\alpha=\alpha_{1}+\alpha_{2}-\alpha_{1} \alpha_{2}$.

(v) If the mappings $\left\{T_{i}\right\}_{i=1}^{n}$ are averaged and have a common fixed point, then

$$
\bigcap_{i=1}^{n} \operatorname{Fix}\left(T_{i}\right)=\operatorname{Fix}\left(T_{1} \cdots T_{N}\right)
$$

Lemma 2.6 (see [14], demiclosedness principle) Let $C$ be a nonempty closed and convex subset of a real Hilbert space $H$ and let $S: C \rightarrow C$ be a nonexpansive mapping with $\operatorname{Fix}(S) \neq \emptyset$. If the sequence $\left\{x_{n}\right\} \subseteq C$ converges weakly to $x$ and the sequence $\left\{(I-S) x_{n}\right\}$ converges strongly to $y$, then $(I-S) x=y$; in particular, if $y=0$, then $x \in \operatorname{Fix}(S)$.

Lemma 2.7 (see [15]) Let the sequences $\left\{a_{n}\right\}$ and $\left\{u_{n}\right\}$ of real numbers satisfy

$$
a_{n+1} \leq\left(1+u_{n}\right) a_{n}, \quad \forall n \geq 1,
$$

where $a_{n} \geq 0, u_{n} \geq 0$ and $\sum_{n=1}^{\infty} u_{n}<\infty$. Then

(1) $\lim _{n \rightarrow \infty} a_{n}$ exists;

(2) if $\liminf _{n \rightarrow \infty} a_{n}=0$, then $\lim _{n \rightarrow \infty} a_{n}=0$.

The following lemma gives some characterizations and useful properties of the metric projection $P_{C}$ in a Hilbert space.

For every point $x \in H$, there exists a unique nearest point in $C$, denoted by $P_{C} x$, such that

$$
\left\|x-P_{C} x\right\| \leq\|x-y\|, \quad \forall y \in C,
$$

where $P_{C}$ is called the metric projection of $H$ onto $C$. We know that $P_{C}$ is a nonexpansive mapping of $H$ onto $C$.

Proposition 2.8 For given $x \in H$ and $z \in C$ :

(i) $z=P_{C} x$ if and only if $\langle x-z, y-z\rangle \leq 0$ for all $y \in C$.

(ii) $z=P_{C} x$ if and only if $\|x-z\|^{2} \leq\|x-y\|^{2}-\|y-z\|^{2}$ for all $y \in C$.

(iii) For all $y \in H,\left\langle P_{C} x-P_{C} y, x-y\right\rangle \geq\left\|P_{C} x-P_{C} y\right\|^{2}$.

Lemma 2.9 (see [16]) Let $H$ be a real Hilbert space. Then the following equations hold:

(i) $\|x-y\|^{2}=\|x\|^{2}-\|y\|^{2}-2\langle x-y, y\rangle$ for all $x, y \in H$;

(ii) $\|t x+(1-t) y\|^{2}=t\|x\|^{2}+(1-t)\|y\|^{2}-t(1-t)\|x-y\|^{2}$ for all $t \in[0,1]$ and $x, y \in H$.

Let $K$ be a nonempty closed convex subset of a real Hilbert space $H$ and let $F: K \rightarrow H$ be a monotone mapping. The variational inequality problem (VIP) is to find $x \in K$ such 
that

$$
\langle F x, y-x\rangle \geq 0, \quad \forall y \in K
$$

The solution set of the VIP is denoted by $\operatorname{VIP}(K, F)$. It is well known that

$$
x \in \operatorname{VI}(K, F) \Leftrightarrow x=P_{K}(x-\lambda F x), \quad \forall \lambda>0 .
$$

A set-valued mapping $T: H \rightarrow 2^{H}$ is called monotone if for all $x, y \in H, f \in T x$ and $g \in T y$ imply

$$
\langle x-y, f-g\rangle \geq 0 \text {. }
$$

A monotone mapping $T: H \rightarrow 2^{H}$ is called maximal if its graph $G(T)$ is not properly contained in the graph of any other monotone mapping. It is known that a monotone mapping $T$ is maximal if and only if for $(x, f) \in H \times H,\langle x-y, f-g\rangle \geq 0$ for every $(y, g) \in$ $G(T)$ implies $f \in T x$. Let $F: K \rightarrow H$ be a monotone and $k$-Lipschitz continuous mapping and let $N_{K} v$ be the normal cone to $K$ at $v \in K$, that is,

$$
N_{K} v=\{w \in H:\langle v-u, w\rangle \geq 0, \forall u \in K\} .
$$

Define

$$
T v= \begin{cases}F v+N_{K} v & \text { if } v \in K, \\ \varnothing & \text { if } v \notin K .\end{cases}
$$

Then $T$ is maximal monotone and $0 \in T v$ if and only if $v \in \operatorname{VI}(K, F)$; see [15] for more details.

We can use fixed point algorithms to solve the SFP on the basis of the following observation.

Let $\lambda>0$ and assume that $x^{*} \in \Gamma$. Then $A x^{*} \in Q$, which implies that $\left(I-P_{Q}\right) A x^{*}=0$, and thus $\lambda A^{*}\left(I-P_{Q}\right) A x^{*}=0$. Hence, we have the fixed point equation $\left(I-\lambda A^{*}\left(I-P_{Q}\right) A\right) x^{*}=x^{*}$. Requiring that $x^{*} \in C$, we consider the fixed point equation

$$
P_{C}(I-\lambda \nabla f) x^{*}=P_{C}\left(I-\lambda A^{*}\left(I-P_{Q}\right) A\right) x^{*}=x^{*} .
$$

It is proved in [7, Proposition 3.2] that the solutions of fixed point equation (2.2) are exactly the solutions of the SFP; namely, for given $x^{*} \in H_{1}, x^{*}$ solves the SFP if and only if $x^{*}$ solves fixed point equation (2.2).

Proposition 2.10 (see [12]) Given $x^{*} \in H_{1}$, the following statements are equivalent.

(i) $x^{*}$ solves the SFP;

(ii) $x^{*}$ solves fixed point equation (2.2);

(iii) $x^{*}$ solves the variational inequality problem (VIP) of finding $x^{*} \in C$ such that

$$
\left\langle\nabla f\left(x^{*}\right), x-x^{*}\right\rangle \geq 0, \quad \forall x \in C
$$

where $\nabla f=A^{*}\left(I-P_{Q}\right) A$ and $A^{*}$ is the adjoint of $A$. 
Proof (i) $\Leftrightarrow$ (ii). See the proof in [7, Proposition 3.2].

(ii) $\Leftrightarrow$ (iii). Observe that

$$
\begin{aligned}
P_{C}\left(I-\lambda A^{*}\left(I-P_{Q}\right) A\right) x^{*}=x^{*} & \Leftrightarrow \quad\left\langle\left(I-\lambda A^{*}\left(I-P_{Q}\right) A\right) x^{*}-x^{*}, x-x^{*}\right\rangle \leq 0, \quad \forall x \in C \\
& \Leftrightarrow \quad-\lambda\left\langle A^{*}\left(I-P_{Q}\right) A x^{*}, x-x^{*}\right\rangle \leq 0, \quad \forall x \in C \\
& \Leftrightarrow \quad\left\langle\nabla f\left(x^{*}\right), x-x^{*}\right\rangle \geq 0, \quad \forall x \in C,
\end{aligned}
$$

where $\nabla f=A^{*}\left(I-P_{Q}\right) A$.

Remark 2.11 It is clear from Proposition 2.10 that

$$
\Gamma:=\operatorname{Fix}\left(P_{C}(I-\lambda \nabla f)\right)=\operatorname{VI}(C, \nabla f)
$$

for any $\lambda>0$, where $\operatorname{Fix}\left(P_{C}(I-\lambda \nabla f)\right)$ and $\operatorname{VI}(C, \nabla f)$ denote the set of fixed points of $P_{C}(I-$ $\lambda \nabla f)$ and the solution set of VIP.

\section{Main result}

Theorem 3.1 Let $C$ be a nonempty, closed, and convex subset of a real Hilbert space $H$ and let $T: C \rightarrow C$ be a uniformly L-Lipschitzian and asymptotically quasi-nonexpansive mappings with $\operatorname{Fix}(T) \cap \Gamma \neq \emptyset$ and $\left\{k_{n}\right\} \subset[1, \infty)$ for all $n \in \mathbb{N}$ such that $\sum_{n=1}^{\infty}\left(k_{n}-1\right)<\infty$. Let $\left\{x_{n}\right\}$ and $\left\{y_{n}\right\}$ be the sequences in $C$ generated by the following algorithm:

$$
\left\{\begin{array}{l}
x_{0}=x \in C \quad \text { chosen arbitrarily, } \\
y_{n}=P_{C}\left(I-\lambda_{n} \nabla f_{\alpha_{n}}\right) x_{n}, \\
x_{n+1}=\beta_{n} x_{n}+\left(1-\beta_{n}\right) T^{n} y_{n}, \quad \forall n \geq 0,
\end{array}\right.
$$

where $\nabla f_{\alpha_{n}}=\nabla f+\alpha_{n} I=A^{*}\left(I-P_{Q}\right) A+\alpha_{n} I$, and three sequences $\left\{\alpha_{n}\right\},\left\{\lambda_{n}\right\}$, and $\left\{\beta_{n}\right\}$ satisfy the conditions:

(i) $\sum_{n=1}^{\infty} \alpha_{n}<\infty$,

(ii) $\left\{\lambda_{n}\right\} \subset[a, b]$ for some $a, b \in\left(0, \frac{1}{\|A\|^{2}}\right)$ and $\sum_{n=1}^{\infty}\left|\lambda_{n+1}-\lambda_{n}\right|<\infty$,

(iii) $\left\{\beta_{n}\right\} \subset[c, d]$ for some $c, d \in(0,1)$.

Then the sequences $\left\{x_{n}\right\}$ and $\left\{y_{n}\right\}$ converge weakly to an element $\hat{x} \in \operatorname{Fix}(T) \cap \Gamma$.

Proof We first show that $P_{C}\left(I-\lambda \nabla f_{\alpha}\right)$ is $\zeta$-averaged for each $\lambda_{n} \in\left(0, \frac{2}{\alpha+\|A\|^{2}}\right)$, where

$$
\zeta=\frac{2+\lambda\left(\alpha+\|A\|^{2}\right)}{4} .
$$

Indeed, it is easy to see that $\nabla f=A^{*}\left(I-P_{Q}\right) A$ is $\frac{1}{\|A\|^{2}}$-ism, that is,

$$
\langle\nabla f(x)-\nabla f(y), x-y\rangle \geq \frac{1}{\|A\|^{2}}\|\nabla f(x)-\nabla f(y)\|^{2} .
$$

Observe that

$$
\begin{aligned}
& \left(\alpha+\|A\|^{2}\right)\left\langle\nabla f_{\alpha}(x)-\nabla f_{\alpha}(y), x-y\right\rangle \\
& \quad=\left(\alpha+\|A\|^{2}\right)\left[\alpha\|x-y\|^{2}+\langle\nabla f(x)-\nabla f(y), x-y\rangle\right]
\end{aligned}
$$




$$
\begin{aligned}
= & \alpha^{2}\|x-y\|^{2}+\alpha\langle\nabla f(x)-\nabla f(y), x-y\rangle \\
& +\alpha\|A\|^{2}\|x-y\|^{2}+\|A\|^{2}\langle\nabla f(x)-\nabla f(y), x-y\rangle \\
\geq & \alpha^{2}\|x-y\|^{2}+2 \alpha\langle\nabla f(x)-\nabla f(y), x-y\rangle+\|\nabla f(x)-\nabla f(y)\|^{2} \\
= & \|\alpha(x-y)+\nabla f(x)-\nabla f(y)\|^{2} \\
= & \|\nabla f(x)-\nabla f(y)\|^{2} .
\end{aligned}
$$

Hence, it follows that $\nabla f_{\alpha}=\alpha I+A^{*}\left(I-P_{Q}\right) A$ is $\frac{1}{\alpha+\|A\|^{2}}$-ism. Thus, $\lambda \nabla f_{\alpha}$ is $\frac{1}{\lambda\left(\alpha+\|A\|^{2}\right)}$-ism. By Proposition 2.4(iii) the composite $\left(I-\lambda \nabla f_{\alpha}\right)$ is $\frac{\lambda\left(\alpha+\|A\|^{2}\right)}{2}$-averaged. Therefore, noting that $P_{C}$ is $\frac{1}{2}$-averaged and utilizing Proposition 2.5(iv), we know that for each $\lambda \in\left(0, \frac{2}{\alpha+\|A\|^{2}}\right)$, $P_{C}\left(I-\lambda \nabla f_{\alpha}\right)$ is $\zeta$-averaged with

$$
\zeta=\frac{1}{2}+\frac{\lambda\left(\alpha+\|A\|^{2}\right)}{2}-\frac{1}{2} \cdot \frac{\lambda\left(\alpha+\|A\|^{2}\right)}{2}=\frac{2+\lambda\left(\alpha+\|A\|^{2}\right)}{4} \in(0,1)
$$

This shows that $P_{C}\left(I-\lambda \nabla f_{\alpha}\right)$ is nonexpansive. Furthermore, for $\left\{\lambda_{n}\right\} \in[a, b]$ with $a, b \in$ $\left(0, \frac{1}{\|A\|^{2}}\right)$, utilizing the fact that $\lim _{n \rightarrow \infty} \frac{1}{\alpha_{n}+\|A\|^{2}}=\frac{1}{\|A\|^{2}}$, we may assume that

$$
0<a \leq \lambda_{n} \leq b<\frac{1}{\|A\|^{2}}, \quad \forall n \geq 0 .
$$

Consequently, it follows that for each integer $n \geq 0, P_{C}\left(I-\lambda_{n} \nabla f_{\alpha_{n}}\right)$ is $\zeta_{n}$-averaged with

$$
\zeta_{n}=\frac{1}{2}+\frac{\lambda_{n}\left(\alpha_{n}+\|A\|^{2}\right)}{2}-\frac{1}{2} \cdot \frac{\lambda_{n}\left(\alpha_{n}+\|A\|^{2}\right)}{2}=\frac{2+\lambda_{n}\left(\alpha_{n}+\|A\|^{2}\right)}{4} \in(0,1) .
$$

This immediately implies that $P_{C}\left(I-\lambda_{n} \nabla f_{\alpha_{n}}\right)$ is nonexpansive for all $n \geq 0$.

We divide the remainder of the proof into several steps.

Step 1. We prove that $\left\{x_{n}\right\}$ is bounded. Indeed, we take a fixed $p \in \operatorname{Fix}(T) \cap \Gamma$ arbitrarily. Then we get $P_{C}\left(I-\lambda_{n} \nabla f\right) p=p$ for $\lambda_{n} \in\left(0, \frac{2}{\|A\|^{2}}\right)$. Since $P_{C}$ and $\left(I-\lambda_{n} \nabla f_{\alpha_{n}}\right)$ are nonexpansive mappings, then we have

$$
\begin{aligned}
\left\|y_{n}-p\right\|= & \left\|P_{C}\left(I-\lambda_{n} \nabla f_{\alpha_{n}}\right) x_{n}-P_{C}\left(I-\lambda_{n} \nabla f\right) p\right\| \\
\leq & \left\|P_{C}\left(I-\lambda_{n} \nabla f_{\alpha_{n}}\right) x_{n}-P_{C}\left(I-\lambda_{n} \nabla f_{\alpha_{n}}\right) p\right\| \\
& \quad+\left\|P_{C}\left(I-\lambda_{n} \nabla f_{\alpha_{n}}\right) p-P_{C}\left(I-\lambda_{n} \nabla f\right) p\right\| \\
\leq & \left\|x_{n}-p\right\|+\left\|\left(I-\lambda_{n} \nabla f_{\alpha_{n}}\right) p-\left(I-\lambda_{n} \nabla f\right) p\right\| \\
= & \left\|x_{n}-p\right\|+\left\|\lambda_{n} \nabla f p-\lambda_{n} \nabla f_{\alpha_{n}} p\right\| \\
= & \left\|x_{n}-p\right\|+\lambda_{n}\left\|\nabla f p-\nabla f_{\alpha_{n}} p\right\| \\
= & \left\|x_{n}-p\right\|+\lambda_{n}\left\|\nabla f p-\nabla f p-\alpha_{n} p\right\| \\
\leq & \left\|x_{n}-p\right\|+\alpha_{n} \lambda_{n}\|p\| .
\end{aligned}
$$

Observe that

$$
\begin{aligned}
\left\|x_{n+1}-p\right\| & =\left\|\beta_{n} x_{n}+\left(1-\beta_{n}\right) T^{n} y_{n}-p\right\| \\
& \leq \beta_{n}\left\|x_{n}-p\right\|+\left(1-\beta_{n}\right)\left\|T^{n} y_{n}-p\right\|
\end{aligned}
$$




$$
\begin{aligned}
& \leq \beta_{n}\left\|x_{n}-p\right\|+\left(1-\beta_{n}\right) k_{n}\left\|y_{n}-p\right\| \\
& \leq \beta_{n}\left\|x_{n}-p\right\|+\left(1-\beta_{n}\right) k_{n}\left(\left\|x_{n}-p\right\|+\lambda_{n} \alpha_{n}\|p\|\right) \\
& =\beta_{n}\left\|x_{n}-p\right\|+\left(1-\beta_{n}\right) k_{n}\left\|x_{n}-p\right\|+\left(1-\beta_{n}\right) k_{n} \alpha_{n} \lambda_{n}\|p\| \\
& =\left(1+\left(k_{n}-1\right)\left(1-\beta_{n}\right)\right)\left\|x_{n}-p\right\|+\left(1-\beta_{n}\right) k_{n} \alpha_{n} \lambda_{n}\|p\| .
\end{aligned}
$$

Since $\sum_{n=1}^{\infty}\left(k_{n}-1\right)<\infty$, according to Lemma 2.7 and (i), (ii) and (3.3), we obtain that

$$
\lim _{n \rightarrow \infty}\left\|x_{n}-p\right\| \text { exists for each } p \in \operatorname{Fix}(T) \cap \Gamma .
$$

This implies that $\left\{x_{n}\right\}$ is bounded and $\left\{y_{n}\right\}$ is also bounded.

It follows that

$$
\left\|T^{n} x_{n}-p\right\| \leq k_{n}\left\|x_{n}-p\right\|
$$

Hence $\left\{T^{n} x_{n}-p\right\}$ is bounded.

Step 2. We prove that

$$
\lim _{n \rightarrow \infty}\left\|y_{n}-T y_{n}\right\|=0
$$

In fact, it follows from (3.2) that

$$
\begin{aligned}
\left\|y_{n}-p\right\|^{2} & =\left(\left\|x_{n}-p\right\|+\alpha_{n} \lambda_{n}\|p\|\right)^{2} \\
& \leq\left\|x_{n}-p\right\|^{2}+2 \alpha_{n} \lambda_{n}\|p\|\left\|x_{n}-p\right\|+\alpha_{n}^{2} \lambda_{n}^{2}\|p\|^{2} \\
& =\left\|x_{n}-p\right\|^{2}+\alpha_{n}\left(2 \lambda_{n}\|p\|\left\|x_{n}-p\right\|+\alpha_{n} \lambda_{n}^{2}\|p\|^{2}\right) \\
& =\left\|x_{n}-p\right\|^{2}+\alpha_{n} M,
\end{aligned}
$$

where $M=\sup _{n \geq 0}\left\{2 \lambda_{n}\|p\|\left\|x_{n}-p\right\|+\alpha_{n} \lambda_{n}^{2}\|p\|^{2}\right\}<\infty$.

It follows that

$$
\begin{aligned}
\left\|T^{n} y_{n}-p\right\|^{2} & \leq\left(k_{n}\left\|y_{n}-p\right\|\right)^{2} \\
& =k_{n}^{2}\left\|y_{n}-p\right\|^{2} \\
& =k_{n}^{2}\left\|x_{n}-p\right\|^{2}+\alpha_{n} k_{n}^{2} M .
\end{aligned}
$$

Also, observe that

$$
\begin{aligned}
\left\|x_{n+1}-p\right\|^{2}= & \left\|\beta_{n} x_{n}+\left(1-\beta_{n}\right) T^{n} y_{n}-p\right\|^{2} \\
\leq & \beta_{n}\left\|x_{n}-p\right\|^{2}+\left(1-\beta_{n}\right)\left\|T^{n} y_{n}-p\right\|^{2}-\beta_{n}\left(1-\beta_{n}\right)\left\|T^{n} y_{n}-x_{n}\right\|^{2} \\
\leq & \beta_{n}\left\|x_{n}-p\right\|^{2}+\left(1-\beta_{n}\right)\left(k_{n}^{2}\left\|x_{n}-p\right\|^{2}+\alpha_{n} k_{n}^{2} M\right)-\beta_{n}\left(1-\beta_{n}\right)\left\|T^{n} y_{n}-x_{n}\right\|^{2} \\
= & \beta_{n}\left\|x_{n}-p\right\|^{2}+\left(1-\beta_{n}\right) k_{n}^{2}\left\|x_{n}-p\right\|^{2}+\left(1-\beta_{n}\right) k_{n}^{2} \alpha_{n} M \\
& -\beta_{n}\left(1-\beta_{n}\right)\left\|T^{n} y_{n}-x_{n}\right\|^{2} \\
= & \left(k_{n}^{2}-\beta_{n}\left(k_{n}^{2}-1\right)\right)\left\|x_{n}-p\right\|^{2}+\left(1-\beta_{n}\right) k_{n}^{2} \alpha_{n} M-\beta_{n}\left(1-\beta_{n}\right)\left\|T^{n} y_{n}-x_{n}\right\|^{2} .
\end{aligned}
$$


Hence, we have

$$
\begin{aligned}
& \beta_{n}\left(1-\beta_{n}\right)\left\|T^{n} y_{n}-x_{n}\right\|^{2} \\
& \quad \leq\left(k_{n}^{2}-\beta_{n}\left(k_{n}^{2}-1\right)\right)\left\|x_{n}-p\right\|^{2}-\left\|x_{n+1}-p\right\|^{2}+\left(1-\beta_{n}\right) k_{n}^{2} \alpha_{n} M .
\end{aligned}
$$

By the conditions (i), (iii) and $\lim _{n \rightarrow \infty} k_{n}=1$, we can conclude that

$$
\lim _{n \rightarrow \infty}\left\|T^{n} y_{n}-x_{n}\right\|=0
$$

Consider that since $y_{n}=P_{C}\left(x_{n}-\lambda_{n} \nabla f_{\alpha_{n}} x_{n}\right)$ and by Proposition 2.8(ii), we have

$$
\begin{aligned}
\left\|y_{n}-p\right\|^{2} \leq & \left\|x_{n}-\lambda_{n} \nabla f_{\alpha_{n}}\left(x_{n}\right)-p\right\|^{2}-\left\|x_{n}-\lambda_{n} \nabla f_{\alpha_{n}}\left(x_{n}\right)-y_{n}\right\|^{2} \\
= & \left\|x_{n}-p\right\|^{2}-\left\|x_{n}-y_{n}\right\|^{2}+2 \lambda_{n}\left\langle\nabla f_{\alpha_{n}}\left(x_{n}\right), p-y_{n}\right\rangle \\
= & \left\|x_{n}-p\right\|^{2}-\left\|x_{n}-y_{n}\right\|^{2}+2 \lambda_{n}\left(\left\langle\nabla f_{\alpha_{n}}\left(x_{n}\right)-\nabla f_{\alpha_{n}}(p), p-x_{n}\right\rangle\right. \\
& \left.+\left\langle\nabla f_{\alpha_{n}}(p), p-x_{n}\right\rangle+\left\langle\nabla f_{\alpha_{n}}\left(x_{n}\right), x_{n}-y_{n}\right\rangle\right) \\
\leq & \left\|x_{n}-p\right\|^{2}-\left\|x_{n}-y_{n}\right\|^{2}+2 \lambda_{n}\left(\left\langle\nabla f_{\alpha_{n}}(p), p-x_{n}\right\rangle+\left\langle\nabla f_{\alpha_{n}}\left(x_{n}\right), x_{n}-y_{n}\right\rangle\right) \\
= & \left\|x_{n}-p\right\|^{2}-\left\|x_{n}-y_{n}\right\|^{2}+2 \lambda_{n}\left[\left\langle\left(\alpha_{n} I+\nabla f\right) p, p-x_{n}\right\rangle+\left\langle\nabla f_{\alpha_{n}}\left(x_{n}\right), x_{n}-y_{n}\right\rangle\right] \\
= & \left\|x_{n}-p\right\|^{2}-\left\|x_{n}-y_{n}\right\|^{2}+2 \lambda_{n}\left[\alpha_{n}\left\langle p, p-x_{n}\right\rangle+\left\langle\nabla f_{\alpha_{n}}\left(x_{n}\right), x_{n}-y_{n}\right\rangle\right] \\
= & \left\|x_{n}-p\right\|^{2}-\left\|x_{n}-y_{n}\right\|^{2}+2 \lambda_{n} \alpha_{n}\left\langle p, p-x_{n}\right\rangle+2 \lambda_{n}\left\langle\nabla f_{\alpha_{n}}\left(x_{n}\right), x_{n}-y_{n}\right\rangle \\
= & \left\|x_{n}-p\right\|^{2}-\left\|x_{n}-y_{n}\right\|^{2}+2 \lambda_{n} \alpha_{n}\left\langle p, p-x_{n}\right\rangle-2 \lambda_{n}\left\langle\nabla f_{\alpha_{n}}\left(x_{n}\right), y_{n}-x_{n}\right\rangle \\
= & \left\|x_{n}-p\right\|^{2}-\left\|x_{n}-y_{n}\right\|^{2}+2 \lambda_{n} \alpha_{n}\left\langle p, p-x_{n}\right\rangle-2 \lambda_{n}\left\langle\nabla f_{\alpha_{n}}\left(x_{n}\right), y_{n}-p+p-x_{n}\right\rangle \\
= & \left\|x_{n}-p\right\|^{2}-\left\|x_{n}-y_{n}\right\|^{2}+2 \lambda_{n} \alpha_{n}\left\langle p, p-x_{n}\right\rangle-2 \lambda_{n}\left\langle\nabla f_{\alpha_{n}}\left(x_{n}\right), y_{n}-p\right\rangle \\
& -2 \lambda_{n}\left\langle\nabla f_{\alpha_{n}}\left(x_{n}\right), p-x_{n}\right\rangle \\
\leq & \left\|x_{n}-p\right\|^{2}-\left\|x_{n}-y_{n}\right\|^{2}+2 \lambda_{n} \alpha_{n}\|p\|\left\|p-x_{n}\right\|-2 \lambda_{n}\left\|\nabla f_{\alpha_{n}}\left(x_{n}\right)\right\|\left\|y_{n}-p\right\| \\
& -2 \lambda_{n}\left\|\nabla f_{\alpha_{n}}\left(x_{n}\right)\right\|\left\|p-x_{n}\right\| . \\
&
\end{aligned}
$$

Consequently, utilizing Lemma 2.9(ii) and (3.7), we conclude that

$$
\begin{aligned}
\left\|x_{n+1}-p\right\|^{2}= & \left\|\beta_{n} x_{n}+\left(1-\beta_{n}\right) T^{n} y_{n}-p\right\|^{2} \\
= & \left\|\beta_{n} x_{n}+\left(1-\beta_{n}\right) T^{n} y_{n}-\left(\beta_{n}+\left(1-\beta_{n}\right)\right) p\right\|^{2} \\
= & \left\|\beta_{n} x_{n}+\left(1-\beta_{n}\right) T^{n} y_{n}-\beta_{n} p-\left(1-\beta_{n}\right) p\right\|^{2} \\
= & \left\|\beta_{n}\left(x_{n}-p\right)+\left(1-\beta_{n}\right)\left(T^{n} y_{n}-p\right)\right\|^{2} \\
= & \beta_{n}\left\|x_{n}-p\right\|^{2}+\left(1-\beta_{n}\right)\left\|T^{n} y_{n}-p\right\|^{2}-\beta_{n}\left(1-\beta_{n}\right)\left\|x_{n}-T^{n} y_{n}\right\|^{2} \\
\leq & \beta_{n}\left\|x_{n}-p\right\|^{2}+\left(1-\beta_{n}\right) k_{n}^{2}\left\|y_{n}-p\right\|^{2}-\beta_{n}\left(1-\beta_{n}\right)\left\|x_{n}-T^{n} y_{n}\right\|^{2} \\
= & \beta_{n}\left\|x_{n}-p\right\|^{2}+\left(1-\beta_{n}\right) k_{n}^{2}\left[\left\|x_{n}-p\right\|^{2}-\left\|x_{n}-y_{n}\right\|^{2}+2 \lambda_{n} \alpha_{n}\|p\|\left\|p-x_{n}\right\|\right. \\
& \left.-2 \lambda_{n}\left\|\nabla f_{\alpha_{n}}\left(x_{n}\right)\right\|\left\|y_{n}-p\right\|-2 \lambda_{n}\left\|\nabla f_{\alpha_{n}}\left(x_{n}\right)\right\|\left\|p-x_{n}\right\|\right] \\
& -\beta_{n}\left(1-\beta_{n}\right)\left\|x_{n}-T^{n} y_{n}\right\|^{2}
\end{aligned}
$$




$$
\begin{aligned}
= & \left(\beta_{n}+\left(1-\beta_{n}\right) k_{n}^{2}\right)\left\|x_{n}-p\right\|^{2}-\left(1-\beta_{n}\right) k_{n}^{2}\left\|x_{n}-y_{n}\right\|^{2} \\
& +2\left(1-\beta_{n}\right) k_{n}^{2} \lambda_{n} \alpha_{n}\|p\|\left\|p-x_{n}\right\| \\
& -2\left(1-\beta_{n}\right) k_{n}^{2} \lambda_{n}\left\|\nabla f_{\alpha_{n}}\left(x_{n}\right)\right\|\left\|y_{n}-p\right\| \\
& -2\left(1-\beta_{n}\right) k_{n}^{2} \lambda_{n}\left\|\nabla f_{\alpha_{n}}\left(x_{n}\right)\right\|\left\|p-x_{n}\right\| \\
& -\beta_{n}\left(1-\beta_{n}\right)\left\|x_{n}-T^{n} y_{n}\right\|^{2} \\
= & \left(k_{n}^{2}-\beta_{n}\left(k_{n}^{2}-1\right)\right)\left\|x_{n}-p\right\|^{2}-\left(1-\beta_{n}\right) k_{n}^{2}\left\|x_{n}-y_{n}\right\|^{2} \\
& +2\left(1-\beta_{n}\right) k_{n}^{2} \lambda_{n} \alpha_{n}\|p\|\left\|p-x_{n}\right\| \\
& -2\left(1-\beta_{n}\right) k_{n}^{2} \lambda_{n}\left\|\nabla f_{\alpha_{n}}\left(x_{n}\right)\right\|\left\|y_{n}-p\right\| \\
& -2\left(1-\beta_{n}\right) k_{n}^{2} \lambda_{n}\left\|\nabla f_{\alpha_{n}}\left(x_{n}\right)\right\|\left\|p-x_{n}\right\| \\
& -\beta_{n}\left(1-\beta_{n}\right)\left\|x_{n}-T^{n} y_{n}\right\|^{2} .
\end{aligned}
$$

It follows that we get

$$
\begin{aligned}
& \left(1-\beta_{n}\right) k_{n}^{2}\left\|x_{n}-y_{n}\right\|^{2}-2\left(1-\beta_{n}\right) k_{n}^{2} \lambda_{n} \alpha_{n}\|p\|\left\|p-x_{n}\right\| \\
& \quad+2\left(1-\beta_{n}\right) k_{n}^{2} \lambda_{n}\left\|\nabla f_{\alpha_{n}}\left(x_{n}\right)\right\|\left(\left\|y_{n}-p\right\|+\left\|p-x_{n}\right\|\right)+\beta_{n}\left(1-\beta_{n}\right)\left\|x_{n}-T^{n} y_{n}\right\|^{2} \\
& \quad \leq\left(k_{n}^{2}-\beta_{n}\left(k_{n}^{2}-1\right)\right)\left\|x_{n}-p\right\|^{2}-\left\|x_{n+1}-p\right\|^{2} .
\end{aligned}
$$

So, taking $n \rightarrow \infty$, since $\lim _{n \rightarrow 0} k_{n}=1$, (i)-(iii), (3.6) and (3.8), we can conclude that

$$
\lim _{n \rightarrow 0}\left\|y_{n}-x_{n}\right\|=0
$$

Consider

$$
\begin{aligned}
\left\|x_{n+1}-x_{n}\right\| & =\left\|\beta_{n} x_{n}-x_{n}+\left(1-\beta_{n}\right) T^{n} y_{n}\right\| \\
& =\left\|-\left(1-\beta_{n}\right) x_{n}+\left(1-\beta_{n}\right) T^{n} y_{n}\right\| \\
& \leq\left(1-\beta_{n}\right)\left\|T^{n} y_{n}-x_{n}\right\| .
\end{aligned}
$$

From (3.6) we obtain

$$
\left\|x_{n+1}-x_{n}\right\| \leq\left(1-\beta_{n}\right)\left\|T^{n} y_{n}-x_{n}\right\| \rightarrow 0 \quad(\text { as } n \rightarrow \infty) .
$$

Observe that

$$
\begin{aligned}
\left\|T^{n} y_{n}-y_{n}\right\| & =\left\|T^{n} y_{n}-x_{n}+x_{n}-y_{n}\right\| \\
& \leq\left\|T^{n} y_{n}-x_{n}\right\|+\left\|x_{n}-y_{n}\right\| .
\end{aligned}
$$

So, from (3.6) and (3.9), we get

$$
\lim _{n \rightarrow \infty}\left\|T^{n} y_{n}-y_{n}\right\|=0
$$


We compute that

$$
\begin{aligned}
\left\|y_{n+1}-y_{n}\right\|= & \left\|P_{C}\left(x_{n+1}-\lambda_{n+1} \nabla f_{\alpha_{n+1}} x_{n+1}\right)-P_{C}\left(x_{n}-\lambda_{n} \nabla f_{\alpha_{n}} x_{n}\right)\right\| \\
= & \left\|P_{C}\left(I-\lambda_{n+1} \nabla f_{\alpha_{n+1}}\right) x_{n+1}-P_{C}\left(I-\lambda_{n} \nabla f_{\alpha_{n}}\right) x_{n}\right\| \\
\leq & \left\|P_{C}\left(I-\lambda_{n+1} \nabla f_{\alpha_{n+1}}\right) x_{n+1}-P_{C}\left(I-\lambda_{n+1} \nabla f_{\alpha_{n+1}}\right) x_{n}\right\| \\
& +\left\|P_{C}\left(I-\lambda_{n+1} \nabla f_{\alpha_{n+1}}\right) x_{n}-P_{C}\left(I-\lambda_{n} \nabla f_{\alpha_{n}}\right) x_{n}\right\| \\
\leq & \left\|x_{n+1}-x_{n}\right\|+\left\|\left(I-\lambda_{n+1} \nabla f_{\alpha_{n+1}}\right) x_{n}-\left(I-\lambda_{n} \nabla f_{\alpha_{n}}\right) x_{n}\right\| \\
= & \left\|x_{n+1}-x_{n}\right\|+\left\|x_{n}-\lambda_{n+1} \nabla f_{\alpha_{n+1}} x_{n}-\left(x_{n}-\lambda_{n} \nabla f_{\alpha_{n}} x_{n}\right)\right\| \\
= & \left\|x_{n+1}-x_{n}\right\|+\left\|\lambda_{n} \nabla f_{\alpha_{n}} x_{n}-\lambda_{n+1} \nabla f_{\alpha_{n+1}} x_{n}\right\| \\
= & \left\|x_{n+1}-x_{n}\right\|+\left\|\lambda_{n}\left(\nabla f+\alpha_{n}\right) x_{n}-\lambda_{n+1}\left(\nabla f+\alpha_{n+1}\right) x_{n}\right\| \\
= & \left\|x_{n+1}-x_{n}\right\|+\left\|\lambda_{n} \nabla f x_{n}+\lambda_{n} \alpha_{n} x_{n}-\left(\lambda_{n+1} \nabla f x_{n}+\lambda_{n+1} \alpha_{n+1} x_{n}\right)\right\| \\
= & \left\|x_{n+1}-x_{n}\right\|+\left\|\left(\lambda_{n}-\lambda_{n+1}\right) \nabla f x_{n}+\lambda_{n} \alpha_{n} x_{n}-\lambda_{n+1} \alpha_{n+1} x_{n}\right\| \\
= & \left\|x_{n+1}-x_{n}\right\|+\|\left(\lambda_{n}-\lambda_{n+1}\right) \nabla f x_{n}+\lambda_{n} \alpha_{n} x_{n}-\lambda_{n} \alpha_{n+1} x_{n} \\
& +\lambda_{n} \alpha_{n+1} x_{n}-\lambda_{n+1} \alpha_{n+1} x_{n} \| \\
= & \left\|x_{n+1}-x_{n}\right\|+\|\left(\lambda_{n}-\lambda_{n+1}\right) \nabla f x_{n}+\lambda_{n}\left(\alpha_{n}-\alpha_{n+1}\right) x_{n} \\
& +\left(\lambda_{n}-\lambda_{n+1}\right) \alpha_{n+1} x_{n} \| \\
\leq & \left\|x_{n+1}-x_{n}\right\|+\left|\lambda_{n}-\lambda_{n+1}\right|\left\|\nabla f x_{n}\right\|+\lambda_{n}\left|\alpha_{n}-\alpha_{n+1}\right|\left\|x_{n}\right\| \\
& +\alpha_{n+1}\left|\lambda_{n}-\lambda_{n+1}\right|\left\|x_{n}\right\| .
\end{aligned}
$$

From the conditions (i), (ii) and (3.11), we obtain that

$$
\left\|y_{n+1}-y_{n}\right\| \rightarrow 0 \quad(\text { as } n \rightarrow \infty) .
$$

Since $T$ is uniformly $L$-Lipschitzian continuous, then

$$
\begin{aligned}
\left\|y_{n}-T y_{n}\right\| & \leq\left\|y_{n}-y_{n+1}\right\|+\left\|y_{n+1}-T^{n+1} y_{n+1}\right\|+\left\|T^{n+1} y_{n+1}-T^{n+1} y_{n}\right\|+\left\|T^{n+1} y_{n}-T y_{n}\right\| \\
& \leq\left\|y_{n}-y_{n+1}\right\|+\left\|y_{n+1}-T^{n+1} y_{n+1}\right\|+L\left\|y_{n}-y_{n+1}\right\|+L\left\|T^{n} y_{n}-y_{n}\right\| .
\end{aligned}
$$

Since $\lim _{n \rightarrow \infty}\left\|y_{n+1}-y_{n}\right\|=0$ and $\lim _{n \rightarrow \infty}\left\|y_{n}-T^{n} y_{n}\right\|=0$, it follows that

$$
\lim _{n \rightarrow \infty}\left\|y_{n}-T y_{n}\right\|=0
$$

Step 3. We show that $\hat{x} \in \operatorname{Fix}(T) \cap \Gamma$.

Since $\nabla f=A^{*}\left(I-P_{Q}\right) A$ is Lipschitz continuous, from (3.9), we have

$$
\lim _{n \rightarrow \infty}\left\|\nabla f\left(x_{n}\right)-\nabla f\left(y_{n}\right)\right\|=0
$$

Since $\left\{x_{n}\right\}$ is bounded, there is a subsequence $\left\{x_{n_{i}}\right\}$ of $\left\{x_{n}\right\}$ that converges weakly to some $\hat{x}$.

First, we show that $\hat{x} \in \Gamma$. Since $\left\|x_{n}-y_{n}\right\| \rightarrow 0$, it is known that $y_{n_{i}} \rightarrow \hat{x}$. 
Put

$$
S w_{1}= \begin{cases}\nabla f w_{1}+N_{C} w_{1} & \text { if } w_{1} \in C, \\ \varnothing & \text { if } w_{1} \notin C,\end{cases}
$$

where $N_{C} w_{1}=\left\{z \in H_{1}:\left\langle w_{1}-u, z\right\rangle \geq 0, \forall u \in C\right\}$. Then $S$ is maximal monotone and $0 \in S w_{1}$ if and only if $w_{1} \in \mathrm{VI}(C, \nabla f)$; (see [17]) for more details. Let $\left(w_{1}, z\right) \in G(S)$, we have

$$
z \in S w_{1}=\nabla f w_{1}+N_{C} w_{1}
$$

and hence

$$
z-\nabla f w_{1} \in N_{C} w_{1}
$$

So, we have

$$
\left\langle w_{1}-u, z-\nabla f w_{1}\right\rangle \geq 0, \quad \forall u \in C .
$$

On the other hand, from

$$
y_{n}=P_{C}\left(I-\lambda_{n} \nabla f_{\alpha_{n}}\right) x_{n} \quad \text { and } \quad w_{1} \in C \text {, }
$$

we have

$$
\left\langle x_{n}-\lambda_{n} \nabla f_{\alpha_{n}} x_{n}-y_{n}, y_{n}-w_{1}\right\rangle \geq 0
$$

and

$$
\left\langle w_{1}-y_{n}, \frac{y_{n}-x_{n}}{\lambda_{n}}+\nabla f_{\alpha_{n}} x_{n}\right\rangle \geq 0 .
$$

Therefore, from $z-\nabla f w_{1} \in N_{C} w_{1}$ and $y_{n_{i}} \in C$, it follows that

$$
\begin{aligned}
\left\langle w_{1}-y_{n_{i}}, z\right\rangle \geq & \left\langle w_{1}-y_{n_{i}}, \nabla f w_{1}\right\rangle \\
\geq & \left\langle w_{1}-y_{n_{i}}, \nabla f w_{1}\right\rangle-\left\langle w_{1}-y_{n_{i}}, \frac{y_{n_{i}}-x_{n_{i}}}{\lambda_{n_{i}}}+\nabla f_{\alpha_{n_{i}}} x_{n_{i}}\right\rangle \\
= & \left\langle w_{1}-y_{n_{i}}, \nabla f w_{1}\right\rangle-\left\langle w_{1}-y_{n_{i}}, \frac{y_{n_{i}}-x_{n_{i}}}{\lambda_{n_{i}}}+\nabla f x_{n_{i}}\right\rangle \\
& -\alpha_{n_{i}}\left\langle w_{1}-y_{n_{i}}, x_{n_{i}}\right\rangle \\
= & \left\langle w_{1}-y_{n_{i}}, \nabla f w_{1}-\nabla f y_{n_{i}}\right\rangle+\left\langle w_{1}-y_{n_{i}}, \nabla f y_{n_{i}}-\nabla f x_{n_{i}}\right\rangle \\
& -\left\langle w_{1}-y_{n_{i}}, \frac{y_{n_{i}}-x_{n_{i}}}{\lambda n_{n_{i}}}\right\rangle-\alpha_{n_{i}}\left\langle w_{1}-y_{n_{i}}, x_{n_{i}}\right\rangle \\
\geq & \left\langle w_{1}-y_{n_{i}}, \nabla f y_{n_{i}}-\nabla f x_{n_{i}}\right\rangle-\left\langle w_{1}-y_{n_{i}}, \frac{y_{n_{i}}-x_{n_{i}}}{\lambda_{n_{i}}}\right\rangle \\
& -\alpha_{n_{i}}\left\langle w_{1}-y_{n_{i}}, x_{n_{i}}\right\rangle .
\end{aligned}
$$


Hence, we obtain

$$
\left\langle w_{1}-\hat{x}, z\right\rangle \geq 0 \quad \text { as } i \rightarrow \infty \text {. }
$$

Since $S$ is maximal monotone, we have $\hat{x} \in S^{-1} 0$, and hence $\hat{x} \in \operatorname{VI}(C, \nabla f)$. Thus, it is clear that $\hat{x} \in \Gamma$.

Next, we show that $\hat{x} \in \operatorname{Fix}(T)$. Indeed, since $y_{n_{i}} \rightarrow \hat{x}$ and $\left\|y_{n_{i}}-T y_{n_{i}}\right\| \rightarrow 0$ by (3.14) and Lemma 2.6, we get $\hat{x} \in \operatorname{Fix}(T)$. Therefore, we have $\hat{x} \in \operatorname{Fix}(T) \cap \Gamma$.

Let $\left\{x_{n_{j}}\right\}$ be another subsequence of $\left\{x_{n}\right\}$ such that $\left\{x_{n_{j}}\right\} \rightarrow \bar{x}$. Then $\bar{x} \in \operatorname{Fix}(T) \cap \Gamma$. Let us show that $\hat{x}=\bar{x}$. Assume that $\hat{x} \neq \bar{x}$. From the Opial condition [18], we have

$$
\begin{aligned}
\lim _{n \rightarrow \infty}\left\|x_{n}-\hat{x}\right\| & =\lim _{n_{i} \rightarrow \infty} \inf \left\|x_{n_{i}}-\hat{x}\right\| \\
& <\lim _{n_{i} \rightarrow \infty} \inf \left\|x_{n_{i}}-\bar{x}\right\| \\
& =\lim _{n \rightarrow \infty}\left\|x_{n}-\bar{x}\right\| \\
& =\lim _{n_{j} \rightarrow \infty} \inf \left\|x_{n_{j}}-\bar{x}\right\| \\
& <\lim _{n_{j} \rightarrow \infty} \inf \left\|x_{n_{j}}-\hat{x}\right\| \\
& =\lim _{n \rightarrow \infty}\left\|x_{n}-\hat{x}\right\| .
\end{aligned}
$$

This is a contradiction. Thus, we have $\hat{x}=\bar{x}$. This implies

$$
x_{n} \rightarrow \hat{x} \in \operatorname{Fix}(T) \cap \Gamma \text {. }
$$

Further, from $\left\|x_{n}-y_{n}\right\| \rightarrow 0$, it follows that $y_{n} \rightarrow \hat{x}$. This shows that both sequences $\left\{x_{n}\right\}$ and $\left\{y_{n}\right\}$ converge weakly to $\hat{x} \in \operatorname{Fix}(T) \cap \Gamma$. This completes the proof.

Utilizing Theorem 3.1, we have the following new results in the setting of real Hilbert spaces.

Take $T^{n} \equiv I$ (identity mappings) in Theorem 3.1. Therefore the conclusion follows.

Corollary 3.2 Let $C$ be a nonempty, closed, and convex subset of a real Hilbert space $H$. Suppose that $\Gamma \neq \emptyset$. Let $\left\{x_{n}\right\}$ be a sequence in $C$ generated by the following algorithm:

$$
\left\{\begin{array}{l}
x_{0}=x \in C \quad \text { chosen arbitrarily, } \\
x_{n+1}=\beta_{n} x_{n}+\left(1-\beta_{n}\right) P_{C}\left(I-\lambda_{n} \nabla f_{\alpha_{n}}\right) x_{n}, \quad \forall n \geq 0,
\end{array}\right.
$$

where $\nabla f_{\alpha_{n}}=\nabla f+\alpha_{n} I=A^{*}\left(I-P_{Q}\right) A+\alpha_{n} I$, and the sequences $\left\{\alpha_{n}\right\},\left\{\lambda_{n}\right\}$, and $\left\{\beta_{n}\right\}$ satisfy the conditions:

(i) $\sum_{n=1}^{\infty} \alpha_{n}<\infty$

(ii) $\left\{\lambda_{n}\right\} \subset[a, b]$ for some $a, b \in\left(0, \frac{1}{\|A\|^{2}}\right)$ and $\sum_{n=1}^{\infty}\left|\lambda_{n+1}-\lambda_{n}\right|<\infty$,

(iii) $\left\{\beta_{n}\right\} \subset[c, d]$ for some $c, d \in(0,1)$.

Then the sequence $\left\{x_{n}\right\}$ converges weakly to an element $\hat{x} \in \Gamma$.

Take $P_{C} \equiv I($ identity mappings) in Theorem 3.1. Therefore the conclusion follows. 
Corollary 3.3 Let $C$ be a nonempty, closed, and convex subset of a real Hilbert space $H$ and let $T: C \rightarrow C$ be a uniformly L-Lipschitzian and quasi-nonexpansive mapping with $\operatorname{Fix}(T) \neq \emptyset$ and $\left\{k_{n}\right\} \subset[1, \infty)$ for all $n \in \mathbb{N}$ such that $\sum_{n=1}^{\infty}\left(k_{n}-1\right)<\infty$. Let $\left\{x_{n}\right\}$ be the sequence in $C$ generated by the following algorithm:

$$
\left\{\begin{array}{l}
x_{0}=x \in C \quad \text { chosen arbitrarily, } \\
x_{n+1}=\beta_{n} x_{n}+\left(1-\beta_{n}\right) T^{n} x_{n}, \quad \forall n \geq 0,
\end{array}\right.
$$

and let the sequence $\left\{\beta_{n}\right\}$ satisfy the condition $\left\{\beta_{n}\right\} \subset[c, d]$ for some $c, d \in(0,1)$. Then the sequence $\left\{x_{n}\right\}$ converges weakly to an element $\hat{x} \in \operatorname{Fix}(T)$.

Remark 3.4 Theorem 3.1 improves and extends [7, Theorem 5.7] in the following aspects:

(a) The iterative algorithm [7, Theorem 5.7] is extended for developing our relaxed extragradient algorithm with regularization in Theorem 3.1.

(b) The technique of proving weak convergence in Theorem 3.1 is different from that in [7, Theorem 5.7] because of our technique to use asymptotically quasi-nonexpansive mappings and the property of maximal monotone mappings.

(c) The problem of finding a common element of $\operatorname{Fix}(T) \cap \Gamma$ for asymptotically quasi-nonexpansive mappings which is more general than that for nonexpansive mappings and the problem of finding a solution of the SFP in [7, Theorem 5.7].

\section{Competing interests}

The authors declare that they have no competing interests.

\section{Authors' contributions}

All authors contributed equally and significantly in writing this paper. All authors read and approved the final manuscript.

\section{Acknowledgements}

The authors thank the referee for comments and suggestions on this manuscript. The first author was supported by the Thailand Research Fund through the Royal Golden Jubilee Ph.D. Program (Grant No. PHD/0033/2554) and the King Mongkut's University of Technology Thonburi (KMUTT). Moreover, this study was supported by the Higher Education Research Promotion and National Research University Project of Thailand, Office of the Higher Education Commission (Under Grant No. NRU56000508).

Received: 10 April 2013 Accepted: 21 June 2013 Published: 13 July 2013

\section{References}

1. Censor, Y, Elving, T: A multiprojection algorithm using Bregman projections in product space. Numer. Algorithms 8 , 221-239 (1994)

2. Byrne, C: Iterative oblique projection onto convex subsets and the split feasibility problem. Inverse Probl. 18,441-453 (2002)

3. Censor, Y, Bortfeld, T, Martin, B, Trofimov, A: A unified approach for inversion problems in intensity-modulated radiation therapy. Phys. Med. Biol. 51, 2353-2365 (2006)

4. Censor, Y, Elving, T, Kopf, N, Bortfeld, T: The multiple-set split feasibility problem and its applications for inverse problem. Inverse Probl. 21, 2071-2084 (2005)

5. Censor, Y, Motova, A, Segal, A: Perturbed projections and subgradient projections for the multiple-set split feasibility problem. J. Math. Anal. Appl. 327, 1244-1256 (2007)

6. Censor, Y, Segal, A: Iterative projection methods in biomedical inverse problem. In: Censor, Y, Jiang, M, Louis, AK (eds.) Mathematical Methods in Biomedical Imaging and Intensity-Modulate Therapy, IMRT, pp. 65-96. Edizioni della Normale, Pisa (2008)

7. Xu, HK: Iterative methods for the split feasibility problem in infinite-dimensional Hilbert spaces. Inverse Probl. 26(10), Article ID 105018 (2010)

8. Landweber, L: An iterative formula for Fredholm integral equations of the first kind. Am. J. Math. 73, 615-625 (1951)

9. Byrne, C: A unified treatment of some iterative algorithms in signal processing and image reconstruction. Inverse Probl. 26, 103-120 (2004)

10. Combettes, PL, Wajs, V: Signal recovery by proximal forward-backward splitting multiscale model. Simulation 4 1168-1200 (2005) 
11. Deepho, J, Kumam, P: A modified Halpern's iterative scheme for solving split feasibility problems. Abstr. Appl. Anal. 2012, Article ID 876069 (2012)

12. Ceng, LC, Ansari, QH, Yao, JC: Relaxed extragradient method for finding minimum-norm solutions of the split feasibility problems. Nonlinear Anal. 75(4), 2116-2125 (2012)

13. Combettes, PL: Solving monotone inclusions via compositions of nonexpansive averaged operator. Optimization 53(5-6), 475-504 (2004)

14. Geobel, K, Kirk, WA: Topics in Metric Fixed Point Theory. Cambridge Studies in Advanced Mathematics, vol. 28. Cambridge University Press, Cambridge (1990)

15. Tan, KK, Xu, HK: Approximating fixed points of nonexpansive mappings by the Ishikawa iteration process. J. Math. Anal. Appl. 178, 301-308 (1993)

16. Marino, G, Xu, HK: Weak and strong convergence theorems for strict pseudo-contractions in Hilbert space. J. Math. Anal. Appl. 329, 336-346 (2007)

17. Rockafellar, RT: On the maximality of sums of nonlinear monotone operators. Trans. Am. Math. Soc. 149, 75-88 (1970)

18. Opial, Z: Weak convergence of the sequence of successive approximations for nonexpansive mappings. Bull. Am. Math. Soc. 73, 591-597 (1967)

doi:10.1186/1029-242X-2013-322

Cite this article as: Deepho and Kumam: Split feasibility and fixed-point problems for asymptotically quasi-nonexpansive mappings. Journal of Inequalities and Applications 2013 2013:322.

\section{Submit your manuscript to a SpringerOpen ${ }^{\circ}$ journal and benefit from:}

- Convenient online submission

- Rigorous peer review

- Immediate publication on acceptance

Open access: articles freely available online

- High visibility within the field

- Retaining the copyright to your article 